\title{
Influence of Deformation and Instability of Borehole on Gas Extraction in Deep Mining Soft Coal Seam
}

\author{
Xue-Bo Zhang $\mathbb{D}^{1,2,3,4}$ Shuai-Shuai Shen, ${ }^{3}$ Xiao-Jun Feng $\mathbb{D}^{4,5}$ Yang Ming $\mathbb{D}^{1,2,3}$ \\ and Jia-jia Liu id $1,2,3$ \\ ${ }^{1}$ State Collaborative Innovation Center of Coal Work Safety and Clean-Efficiency Utilization, Jiaozuo, Henan 454003, China \\ ${ }^{2}$ State Key Laboratory Cultivation Base for Gas Geology and Gas Control, Jiaozuo, Henan 454003, China \\ ${ }^{3}$ College of Safety Science and Engineering, Henan Polytechnic University, Jiaozuo, Henan 454003, China \\ ${ }^{4}$ Henan Shenhuo Group Co., Ltd., Yongcheng 476600, China \\ ${ }^{5}$ School of Safety Engineering, China University of Mining and Technology, Xuzhou 221116, China \\ Correspondence should be addressed to Xiao-Jun Feng; xiaojun.feng@cumt.edu.cn
}

Received 26 November 2020; Revised 5 February 2021; Accepted 23 February 2021; Published 8 March 2021

Academic Editor: Jia Lin

Copyright (c) 2021 Xue-Bo Zhang et al. This is an open access article distributed under the Creative Commons Attribution License, which permits unrestricted use, distribution, and reproduction in any medium, provided the original work is properly cited.

\begin{abstract}
To study the effects of the three deformation instability modes of gas drainage borehole on gas drainage, the deformation instability mechanism of soft coal seams is analyzed, three deformation instability modes are proposed for soft coal seams, namely, complete holes, collapse holes, and plug holes, and a solid-fluid coupling model incorporating dynamic change of borehole suction pressure is established. The results of the study show the following. (1) When there is no borehole deformation (i.e., complete borehole), the suction pressure loss of drainage system in the borehole is very small, whose effect on gas drainage can be neglected. (2) In case of borehole collapse, the suction pressure loss is big at the collapse segment, and the total suction pressure loss of the drainage system in the borehole is bigger than that in the complete hole. However, it is smaller than the suction pressure of the drainage system and exerts limited effect on gas drainage. As the borehole collapse deteriorates, the effective drainage section of the borehole becomes smaller, while the suction pressure loss in the borehole increases continuously; thus, the gas drainage effect continuously worsens. (3) In case of plug hole, a continuous medium forms between the plug segment coal body and the surrounding coal seam, the plug segment drainage pressure turns into coal-bed gas pressure, and effective drainage length of the borehole shortens, seriously affecting the gas drainage effect. The study carries important theoretical guiding significance for improving gas drainage effect and effectively preventing gas disasters.
\end{abstract}

\section{Introduction}

Deeply mined soft coal seams are characterized by high stress, low mechanical strength, high gas content and desorption velocity, great coal seam thickness variation, etc. During extraction drilling construction on soft coal seam, dynamic problems such as spit-out, drilling tool sticking, and jamming often bother, causing large-scale hole collapse and formation of drilling cave [1], which severely restrict drilling depth; after the accomplishment of hole drilling, influenced by poor tamper resistance capacity of coal mass, the hole wall may deform, fall, or even collapse under crustal stress; moreover, with extraction going on, soft coal mass may creep and cause hole diameter to shrink or even to clog, which may block gas discharge and flow channel [2-4], and severely impact on gas extraction efficiency. Deformation, instability, collapse, etc. of borehole can all be attributed to dynamic instability caused by redistribution of stress field and flow field of gas-bearing coal around the borehole [5], i.e., instability failure of borehole wall. The study on the effect of deformation instability of gas drainage borehole on high-stress soft coal seam means important theoretical guiding significance for solving the problem of highstress soft coal seam in borehole instability and collapse and for effectively improving gas drainage effect. 
Many scholars both at home and abroad have studied the deformation and instability disciplines of coal rocks around the extraction boreholes [6-20]. Tezuka and Niitsuma [6] proposed some borehole stability models and conducted theoretical analysis on the stability of borehole wall based on such models. Wang et al. [7] established the mechanical model of drilling hole instability and researched the destruction modes and instability characteristics of borehole bottom and coal mass nearby borehole wall. Shengqi et al. $[8,9]$ studied the influence of fracture dip angle on the mechanical properties of sandstone under uniaxial compression by using sandstone with pore fractures as research object and studied the crack growth characteristics and its influence on the stress strain curve of sandstone with combined defects of single fracture, double fracture, and circular holes using acoustic emission and digital photography. Cheng et al. [10] analyzed the instability and deformation mechanisms of boreholes on soft outburst coal seams under coal mines and pointed out the main roots for the frequent occurrence of destruction and instability, hole collapse, and difficulty in hole formation in the weak hole wall structure after fracturing drilling in coal seam construction. Yao et al. [11] adopted Kastner formula and utilized numerical simulation method to research the variation disciplines of stress field, displacement field, and plastic failure area of borehole. Hao et al. [12] established the viscoelastic-plastic softening model of coal mass around borehole, conducted the comparative analysis on the pressure relief effects of boreholes in soft and hard coal seams, and researched the variation discipline of borehole diameter. Predecessors have not yet studied the effect of borehole deformation, instability, and collapse on distribution law of suction pressure of the drainage system as well as drainage volume.

The results show that many achievements have been made on borehole instability, but the effect of borehole deformation instability collapse on the distribution of negative pressure and pumping capacity has not been studied. Targeting at the practical problem of easy deformation and instability of gas drainage borehole in highstress loose coal seams, this paper aims to analyze the mechanism of borehole deformation and instability, put forward the model of borehole deformation and instability, and establish a solid-fluid coupling model considering the dynamic change of borehole negative pressure to analyze the effect of different borehole instability modes on gas drainage. The study carries important theoretical guiding significance for optimizing arrangement of gas drainage borehole, improving gas drainage effect, and effectively preventing gas disasters.

\section{Study on Mechanism and Mode of Deformation Instability of Gas Drainage Borehole}

2.1. Mechanism of Deformation Instability of Gas Drainage Borehole. There are natural factors and engineering factors causing deformation instability of borehole. Fundamentally speaking, instability failure of borehole means that of coalrock mass around the borehole, which is a mechanical instability process. The essence is instability failure caused by inability of coal-rock mass strength to withstand the applied stress; in other words, ground stress is the root cause of borehole instability. Deformation failure of the surrounding coal-rock mass follows the formation of gas drainage boreholes, which mainly includes the two stages: formation of plastic zone and rupture zone and borehole collapse.

(1) As shown in Figure 1(a), the borehole results in elastic zone, plastic zone, and rupture zone from the outside to the inside, the coal body strength in the rupture zone is significantly lower than the virgin rock stress, and the pressure relief zone caused by the drilling construction is mainly concentrated within the rupture zone.

(2) With the continuous extension of time, the deformation of the coal body in the rupture zone and plastic zone further increases, while the coal body strength in the two zones further lowers. When the cohesive force and friction between the coal blocks cannot resist deformation pressure and weight of the internal coal-rock mass, the broken coal body around the borehole will fall and collapse into the borehole. The deformation resistance of the compacted coal body in the collapse zone continuously grows until it can balance the deformation pressure transmitted by the rupture zone when new balance of forces emerges and coal body in each zone maintains relative stability. The final distribution of the deformation instability in each area is shown in Figure 1(b). The fracture surface is in irregular shape after instability collapse of the borehole. The fracture surface size has close relation to load stress, coal body strength, and expansion coefficient of collapsed coal body and time.

2.2. Mode of Deformation Instability of Gas Drainage Borehole. The effect of borehole gas drainage mainly concerns suction pressure of the drainage system, borehole diameter, and permeability of the surrounding coal body. Previous studies found that borehole deformation instability exerts little effect on permeability of surrounding coal body, and the main influencing factor is borehole diameter, i.e., the size of effective flow cross-sectional area of the gas. Therefore, this paper classifies borehole deformation instability modes based on bore diameter after borehole instability. Considering that both borehole shrinkage and hole collapse will occur in gas drainage borehole of deeply mined soft coal seams, this paper classifies deformation instability of gas drainage borehole into complete borehole, collapse hole, and plug hole as shown in Figure 2.

The complete hole means the borehole wall is intact. At this time, there is no deformation of borehole which remains in a quasicircular shape. The collapse hole means the wall surface around the borehole has fallen and collapsed, the fallen coal dust is accumulated on the wall surface below the 


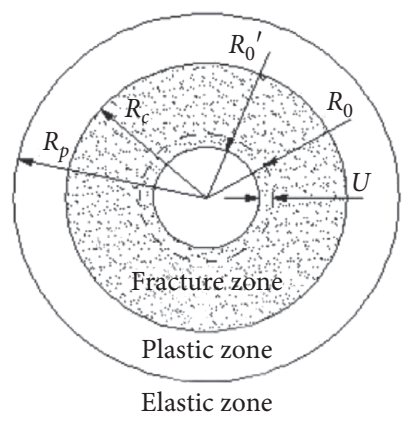

(a)

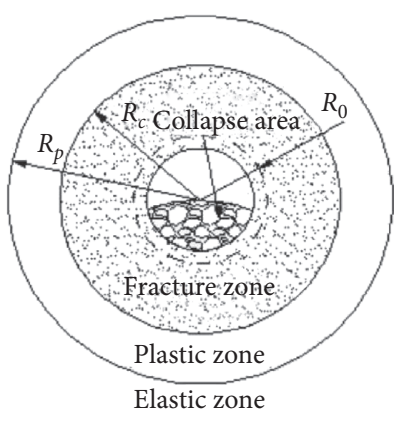

(b)

Figure 1: Sketch map of unstable deformation area of coal seam around borehole. (a) Before the borehole collapses. (b) After the borehole collapses. $R_{0}$, borehole radius before instability; $R_{c}$, radius of fracture zone; $R_{p}$, radius of plastic zone; $R_{0}^{\prime}$, borehole radius after instability; $U$, radial deformation of coal body.

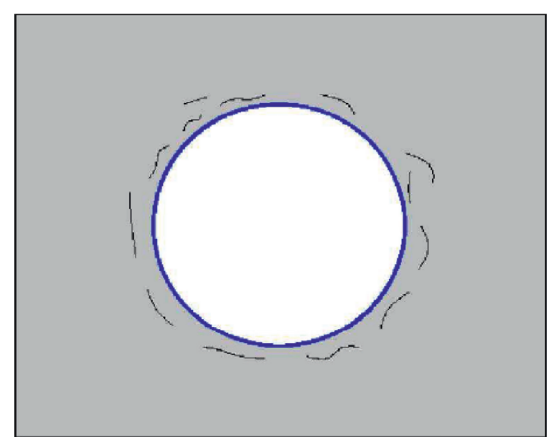

(a)

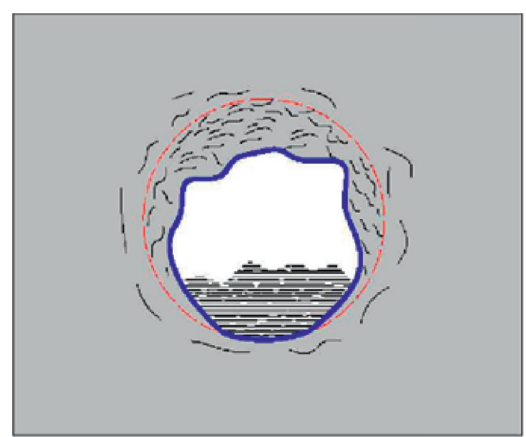

(b)

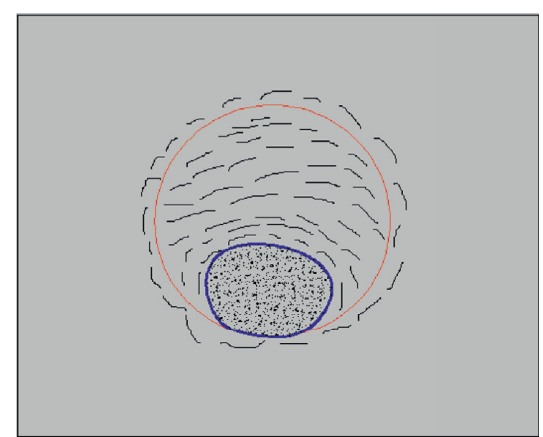

(c)

FIgURE 2: Scheme of borehole deformation and instability. (a) Complete hole. (b) Collapse hole. (c) Blocked hole.

hole, making the effective cross-sectional area of circulation in the hole smaller, local drainage resistance increased, and the drainage flow decreased. The plug hole means the borehole wall surface undergoes sharp collapse, and the collapsed coal dust completely blocks the gas flow passage, making it extremely difficult to extract the gas. Next, gas operation under the three modes of deformation instability of gas drainage borehole is numerically simulated to analyze the effect of borehole instability.

\section{Establishment of Theoretical Model for Borehole Gas Drainage}

3.1. Basic Hypothesis. The following basic hypotheses are introduced to establish the solid-fluid coupling model describing the gas drainage process: (1) the coal seam is an isotropic elastic medium; (2) the gas coal seam is in saturated single-phase adsorption state; (3) the gas flow in the coal seam is isothermal flow that follows the modified Darcy's law; (4) the adsorption and desorption of gas follow Langmuir equation; (5) deformation of the gas-bearing coal seam is a small deformation.
3.2. Coal Seam Deformation Control Equation. If we view coal-rock mass as a linear body, considering the pore pressure in the coal seam and the expansion stress generated by gas adsorption, the stress equilibrium equation can be obtained according to Terzaghi's effective stress principle:

$$
\sigma_{i j, j}^{\prime}+\left(n p \delta_{i j}\right)_{j}+\left(\frac{2 a \rho_{s} R T \ln (1+b p)}{3 V_{m}} \delta_{i j}\right),_{j}+F_{i}=0,
$$

where $n$ is the porosity of the coal seam; $\delta_{i j}$ is a Kronecker symbol; $R$ is the molar gas constant, $J /(\mathrm{mol} \cdot \mathrm{K}) ; T$ is the absolute temperature, $\mathrm{K} ; a$ is the limit adsorption of coalrock mass, $\mathrm{m}^{3} / \mathrm{kg} ; b$ is the adsorption constant, $\mathrm{MPa}^{-1} ; \rho_{s}$ is the apparent density of coal-rock mass, $\mathrm{kg} / \mathrm{m}^{3} ; p$ is the gas pressure, $\mathrm{MPa} ; V_{m}$ is the molar volume, $\mathrm{m}^{3} / \mathrm{mol}$; and $F_{i}$ is the volume force tensor, $\mathrm{N} / \mathrm{m}^{3}$.

Geometric equation can be established according to the Cauchy equation as

$$
\varepsilon_{i j}=\frac{1}{2}\left(u_{i, j}+u_{j, i}\right)
$$

where $R_{i j}$ is the strain tensor of gas-bearing coal and $u_{i}$ is the displacement component, $\mathrm{m}$. 
According to the basic hypothesis for the model construction, the coal body follows the generalized Hooke's law in the elastic deformation stage, i.e.,

$$
\sigma_{i j}^{\prime}=\lambda \delta_{i j} \varepsilon_{v}+2 G \varepsilon_{i j}
$$

where $\lambda$ is the Lame constant; $\varepsilon_{v}$ is the volumetric strain; and $G$ is the shear modulus.

The deformation control equation of the solid-fluid coupling model for gas-bearing coal body can be obtained by integration of formulas (1) (3):

$$
(\lambda+G) u_{j, j i}+G u_{i, j j}+n p_{,_{i}}+\left(\frac{2 a \rho_{s} R T \ln (1+b p)}{3 V_{m}}\right),_{i}+F_{i}=0 .
$$

3.3. Dynamic Model of Coal Seam Porosity and Permeability. In view of the coal body deformation caused by gas pressure, the calculation formula of porosity in the elastic phase of gas-bearing coal rock considering coal body deformation can be obtained according to the definition of porosity $n$ :

$$
n=1-\frac{\left(1-n_{0}\right)}{1+\varepsilon_{v}}\left(1-\frac{\Delta p}{k_{s}}\right)
$$

where $k_{s}$ is the bulk modulus of the coal body, MPa; $\Delta p$ is the change of the gas pressure; $\varepsilon_{v}$ is the volume strain; and $n_{0}$ is the initial porosity of the coal seam.

With full consideration to the deformation of gas coal rock, gas pressure change of pore, and the effect of pore volume change on permeability, the permeability calculation formula can be obtained using Kozeny-Carman equation:

$$
k=\frac{k_{0}}{1+\varepsilon_{v}}\left[1+\frac{\varepsilon_{v}+\Delta p\left(1-n_{0}\right) / k_{s}}{n_{0}}\right]^{3},
$$

where $k$ is the coal seam permeability, $\mathrm{m}^{2}$, and $k_{0}$ is the initial permeability of coal seam, $\mathrm{m}^{2}$.

3.4. Coal Seam Gas Migration Control Equation. By combining the modified Darcy's law (Klinkenberg effect incorporated), the gas content equation, the continuity equation, and the gas state equation, the coal-bed gas migration control equation incorporating seepage and adsorption gas analysis can be obtained.

$$
\begin{aligned}
& 2\left[n+\frac{p(1-n)}{k_{s}}+\frac{a b p_{0}}{(1+b p)^{2}}\right] \frac{\partial p}{\partial t}-\nabla\left[\frac{k}{\mu}\left(1+\frac{m}{p}\right) \nabla p^{2}\right] \\
& \quad+2(1-n) p \frac{\partial \varepsilon_{v}}{\partial t}=0,
\end{aligned}
$$

where $\mu$ is the dynamic viscosity coefficient of gas, Pa.s, and $m$ is the Klinkenberg factor.

3.5. Suction Pressure Loss Calculation Model for Gas Drainage Borehole. As gas discharges along the borehole, gas flow in the hole is a variable mass flow. Since pressure loss in the variable mass flow can only be calculated after obtaining experimental coefficients, the gas flow in the borehole is simplified as pipeline constant mass flow to facilitate calculation. That is, the borehole is divided into several segments as shown in Figure 3. The suction pressure loss in the borehole is obtained via piecewise calculation of suction pressure of the drainage system from the aperture to the hole bottom, as shown in formula (8). In suction pressure loss calculation of each segment, average flow rate is used to replace the actual one, so that suction pressure loss along the borehole can be calculated using formula (9).

$$
\begin{aligned}
p_{i} & =p_{d}+\sum_{n=0}^{n=i} \Delta p_{n}, \quad(i=1,2 \ldots n), \\
\Delta p_{n} & =\lambda_{d} \frac{\Delta l}{d} \frac{\rho_{a} v_{n}^{2}}{2},
\end{aligned}
$$

where $p_{d}$ is the suction pressure of the drainage system at the aperture, $\mathrm{MPa} ; p_{i}$ is the average suction pressure of the drainage system in the $i$ th section of the borehole, MPa; $\Delta p_{n}$ is the suction pressure loss in the $n$th segment of the borehole, $\mathrm{MPa} ; \Delta l$ is the borehole length, $\mathrm{m}$; $d$ is the borehole diameter, $\mathrm{m} ; v_{n}$ is the average flow rate for the $i$ th segment of the borehole, $\mathrm{m} / \mathrm{s} ; \rho_{a}$ is the gas density, $\mathrm{kg} / \mathrm{m}^{3}$; and $\lambda_{d}$ is the drag coefficient along the course.

To calculate the resistance loss in borehole, flow state of the fluid is first judged by Reynolds number Re. Drag coefficient along the course is $\lambda_{d}=64 / \mathrm{Re}$ for laminar flow, while that of turbulent flow can be calculated based on the empirical formula proposed by Aritsuri:

$$
\lambda_{d}=0.11\left(\frac{k_{s}}{d}+\frac{68}{\mathrm{Re}}\right)^{0.25} \text {. }
$$

The local energy loss caused by the deformation and instability of borehole is expressed as a function of flow kinetic energy factor, and the local resistance coefficient is determined according to the calculation method of corresponding local resistance coefficient of underground tunnel.

\section{Effect of Deformation Instability of Gas Drainage Borehole in Deep Mining of Soft Coal Seams}

4.1. Engineering Background and Establishment of Physical Model. The simulated mine is located in the eastern part of the Pingdingshan mining area. The designed production capacity of the mine is 3 million tons per year, and the mineable coal seams in the mine consist of three groups of 4 layers, that is, Ding, $\mathrm{Wu}$, and Ji. The vertical shaft is used for multilevel up and down to develop the whole mine field. The $\mathrm{JI}_{15}-21030$ working face is the first mining face in Ji No.1 mining area, which is located in the Middle East wing of Ji No.1 mining area. The average mining strike length of the working face is $1420 \mathrm{~m}$, the average inclined width is $152 \mathrm{~m}$, the average coal thickness is $5.0 \mathrm{~m}$, the buried depth is $860 \mathrm{~m} \sim 1020 \mathrm{~m}$, and the original gas pressure of coal seam is 1.6 MPa. The coal-bed bedding gas drainage borehole and 


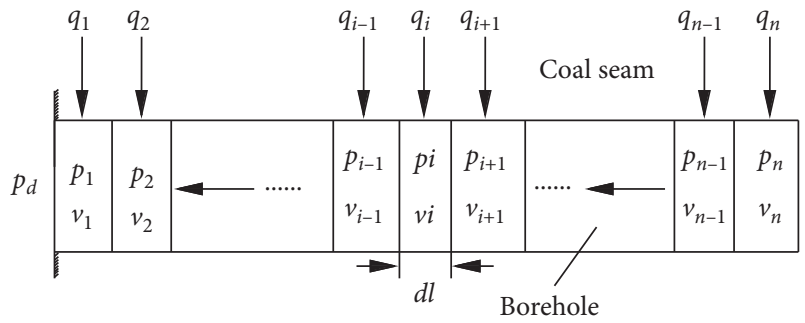

FIGURE 3: Schematic diagram of the calculation of negative pressure in a borehole.

the floor laneway through the layer gas drainage borehole are used in the working face.

Simulation study in this paper is achieved via secondary development of COMSOL Multiphysics. The research object is coal-bed bedding gas drainage borehole process. The established physical model according to the actual condition of working face as shown in Figure 4 is a three-dimensional model of $100 \mathrm{~m} \times 20 \mathrm{~m} \times 5 \mathrm{~m}$. The bedding gas borehole locates in the center of the coal seam with a thickness of $5 \mathrm{~m}$. The gas drainage borehole is $80 \mathrm{~m}$ long (hole sealing is $20 \mathrm{~m}$ ) and $0.094 \mathrm{~m}$ in diameter. The simulation parameters are shown in Table 1.

4.2. Initial Conditions and Boundary Conditions. As regards initial conditions, there is an initial gas pressure of $1.6 \mathrm{MPa}$ inside the coal seam, the suction pressure of the drainage system is $14 \mathrm{kPa}$ at the aperture, and the initial stress state is a result of stress distribution after the open-off cut.

Regarding boundary conditions, gas only flows in the coal seam, the open face has a given atmospheric pressure of $0.1 \mathrm{MPa}$, and the rest of surfaces are with zero-flux, nonventilated boundary. The surrounding of the model is constrained in the form of roller support (displacement in the direction of the restraint normal line), with fixed constraint for the lower part and freedom for the upper part. The upper part bears rock mass with stress at $27.0 \mathrm{MPa}$. Meanwhile, the model has self-weight load.

The boundary of suction pressure of the drainage system at the hole wall is a dynamic function boundary. Every $2 \mathrm{~m}$ borehole is set as an infinitesimal calculation segment. The suction pressure of a segment is obtained by piecewise calculation of suction pressure loss from the aperture to the hole bottom. The calculation model adopts the theoretical model of borehole suction pressure loss established in the paper. The hole wall flow required for the model calculation is obtained by coupling calculation of coal seam gas migration model.

For calculation scheme, simulation of the effect of deformation instability of gas drainage borehole on gas migration law, suction pressure distribution, etc., is carried out in the three following schemes: (1) there is no borehole deformation, i.e., a complete hole; (2) collapsed hole occurs in the rear $40 \mathrm{~m}$, with the section reduced to half of the original; (3) plug hole occurs in the rear $40 \mathrm{~m}$, i.e., rear borehole blockage.

\subsection{Numerical Simulation Results}

4.3.1. Effect of Deformation Instability of Gas Drainage Borehole on Gas Distribution in Peripheral Coal Seam. When there is no borehole deformation (i.e., complete hole), collapsed hole, or plug hole, the gas pressure distribution in the coal seam is shown in Figures 5 7 for different drainage time.

The following can be seen from Figures 5 7. (1) Under the effect of gas drainage borehole, coal-bed gas forms an elliptical pressure relief zone around the borehole; the extension of the drainage time makes the coal-bed gas pressure around the gas drainage borehole decrease continuously and results in constantly increasing pressure relief zone, though the increasing rate gradually decreases and eventually stabilizes. (2) Collapsed hole at $40 \mathrm{~m}$ below the hole bottom exerts little effect on coal-bed gas pressure distribution around the borehole. Compared with coal-bed gas pressure distribution of complete hole, gas pressure distribution in case of collapsed hole differs only at the collaged hole segment, while coal-bed gas pressure distribution at other locations is basically the same as that of complete borehole. (3) Plug hole leads to the change of coal seam permeability near the plug hole segment; that is, the permeability becomes better. This causes great difference in coal-bed gas pressure distribution compared to that of complete hole. In this way, the pressure relief zone in the coal seam in front of the plug segment enlarges, and the drainage pressure in the plug segment becomes positive. The drainage pressure closer to the hole bottom is larger, until it becomes the original gas pressure.

\subsubsection{Effect of Deformation Instability of Gas Drainage} Borehole on Suction Pressure Distribution of the Drainage System. When there is no borehole deformation (i.e., complete hole), collapsed hole, or plug hole, the extraction negative pressure distribution of the drainage system is shown in Figures 8 10 for different drainage time.

The following can be seen from Figures 8 10. (1) Drainage pressure in the borehole gradually decreases with the increasing distance from the aperture, and the decrease range shows a reducing trend. The suction pressure loss of the drainage system is small for complete borehole. As the drainage time increases, the borehole suction pressure loss gradually decreases due to continuous decay of drainage flow. On the 1st day of drainage, suction pressure loss of $80 \mathrm{~m}$ borehole is $22.9 \mathrm{~Pa}$. The figure is only $8.0 \mathrm{~Pa}$ on the 30 th day of drainage. (2) In case of borehole collapse, the decreased borehole section at the collapse segment renders the suction pressure loss of the segment larger, while the suction pressure loss is small for complete segment. The extension of the drainage time makes the drainage flow decay and results in smaller suction pressure loss. After one day of drainage, the suction pressure loss of the first $40 \mathrm{~m}$ complete segment is $27.2 \mathrm{~Pa}$. The figure is $70.8 \mathrm{~Pa}$ for the latter $40 \mathrm{~m}$ collapse segment. Thus, the $80 \mathrm{~m}$ borehole loses $98.0 \mathrm{~Pa}$. After one month of drainage, the suction pressure loss of the first $40 \mathrm{~m}$ complete segment is 9.5 Pa. The figure is $25.3 \mathrm{~Pa}$ for the latter 


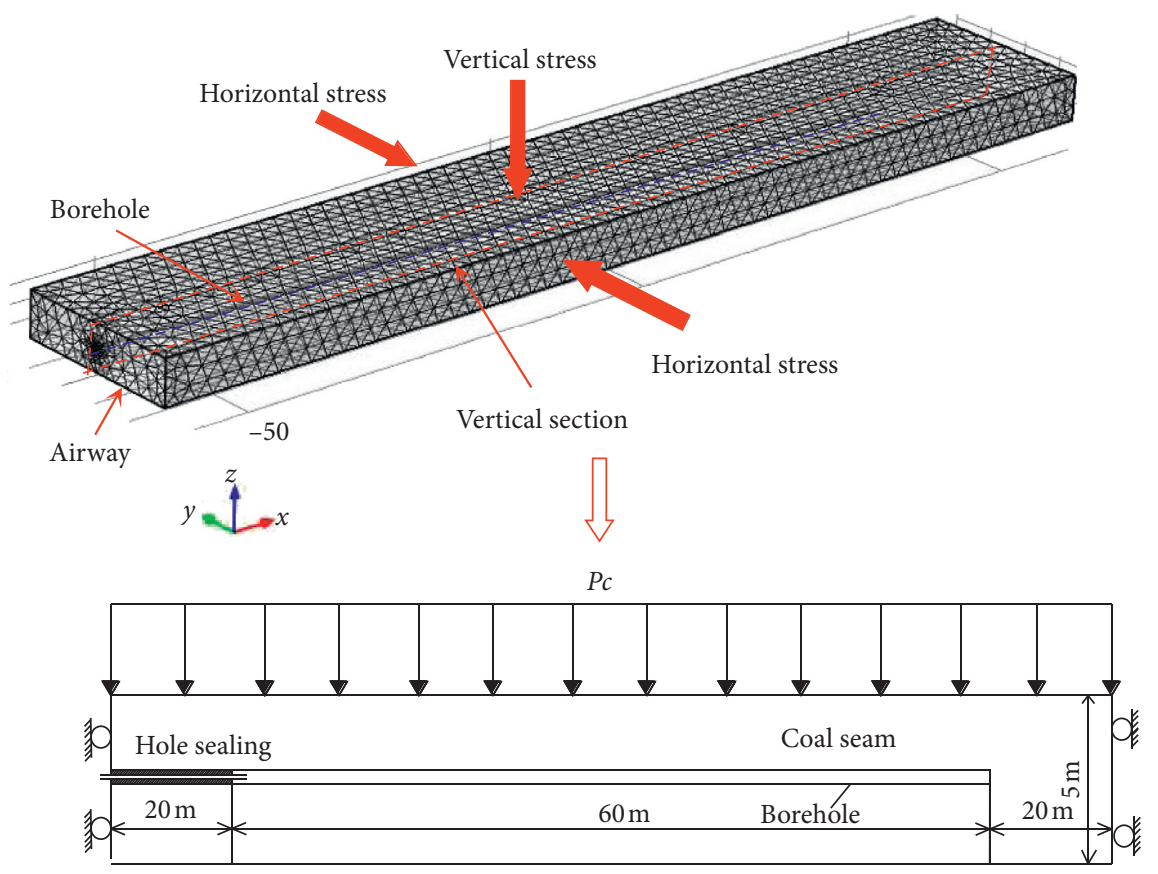

Figure 4: Map of three-dimensional geometrical modeling.

TABLE 1: Simulation parameters.

\begin{tabular}{lcc}
\hline Parameter & Value & Unit \\
\hline Maximum amount of adsorbed gas per unit mass of coal & 28.84 & $\mathrm{~m}^{3} / \mathrm{t}$ \\
Adsorption constant of coal & 0.49 & $\mathrm{MPa}^{-1}$ \\
Gas density under the standard condition & 0.717 & $\mathrm{~kg} / \mathrm{m}^{3}$ \\
Standard atmospheric pressure & 0.1 & $\mathrm{MPa}$ \\
Initial porosity of coal seam & 0.064 & - \\
Initial permeability of coal seam & 0.0227 & $\mathrm{mD}$ \\
Moisture of coal & 0.014 & - \\
Coal ash & 0.127 & -1380 \\
Coal density & 27.0 & $\mathrm{~kg} / \mathrm{m}^{3}$ \\
Crustal stress & 0.339 & $\mathrm{MPa}$ \\
Poisson's ratio of coal & 2863 & - \\
Modulus of elasticity of coal body & $1.08 \times 10^{-5}$ & $\mathrm{MPa}$ \\
Dynamic viscosity of gas & 0.047 & $\mathrm{~Pa} \cdot \mathrm{s}$ \\
Radius of borehole & 1.6 & $\mathrm{~m}$ \\
Initial gas pressure of coal seam & 14 & $\mathrm{MPa}$ \\
Extraction negative pressure & $\mathrm{kPa}$ \\
\hline
\end{tabular}

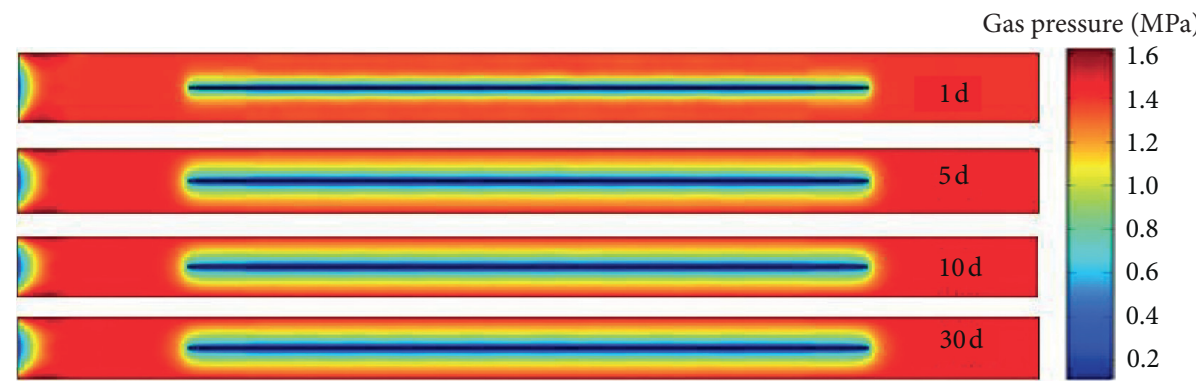

Figure 5: The gas pressure distribution of complete hole in the coal seam.

$40 \mathrm{~m}$ collapse segment. Thus, the $80 \mathrm{~m}$ borehole loses $34.8 \mathrm{~Pa}$, which is very small. As the borehole collapse gradually aggravates, the effective drainage section of the borehole becomes smaller, and the suction pressure loss within the borehole increases, leading to deterioration in gas drainage effect. (3) The drainage pressure changes little for the 


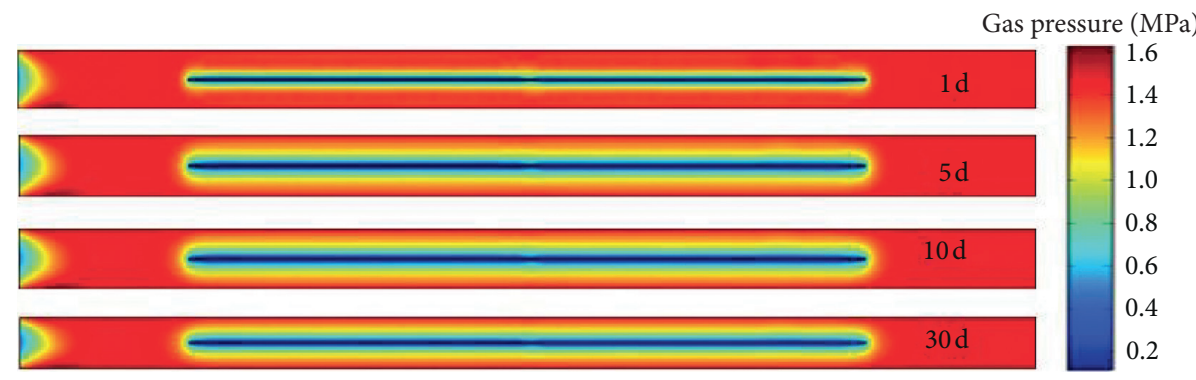

FIGURE 6: The gas pressure distribution of collapsed hole in the coal seam.

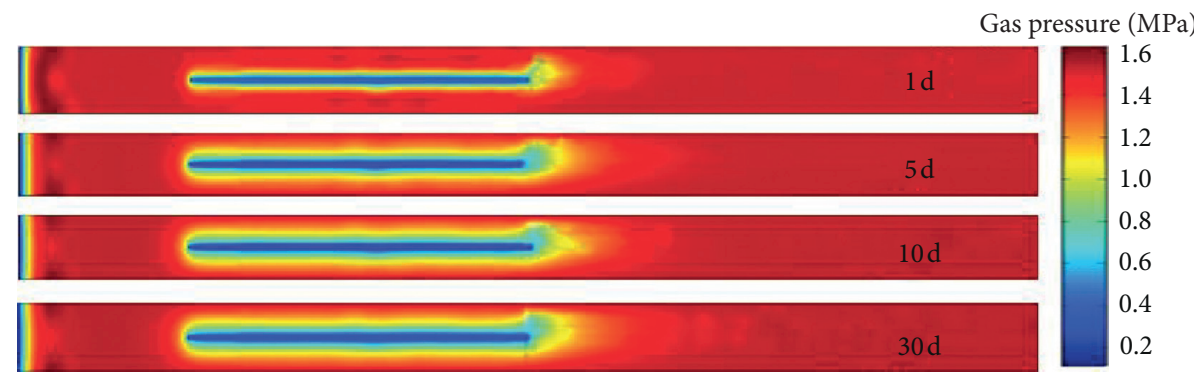

Figure 7: The gas pressure distribution of plug hole in the coal seam.

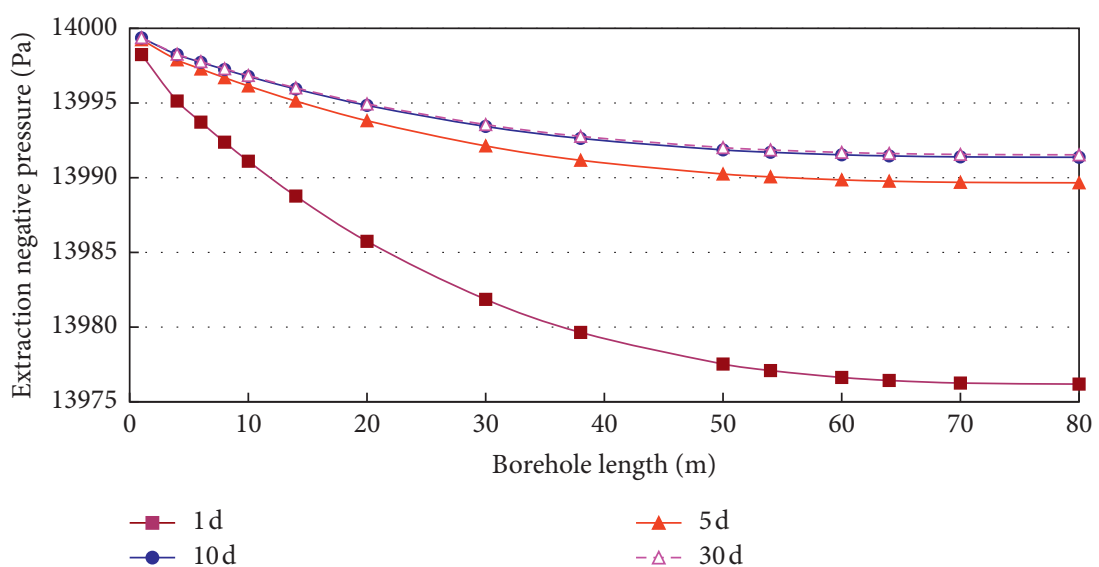

Figure 8: The gas extraction negative pressure distribution of complete hole.

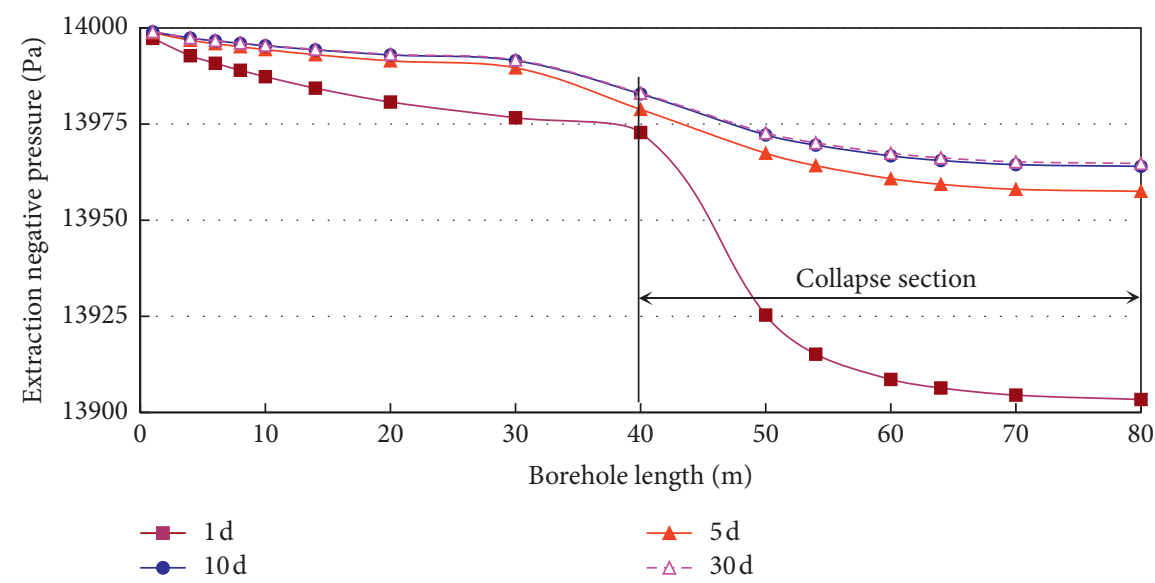

Figure 9: The gas extraction negative pressure distribution of collapsed hole. 


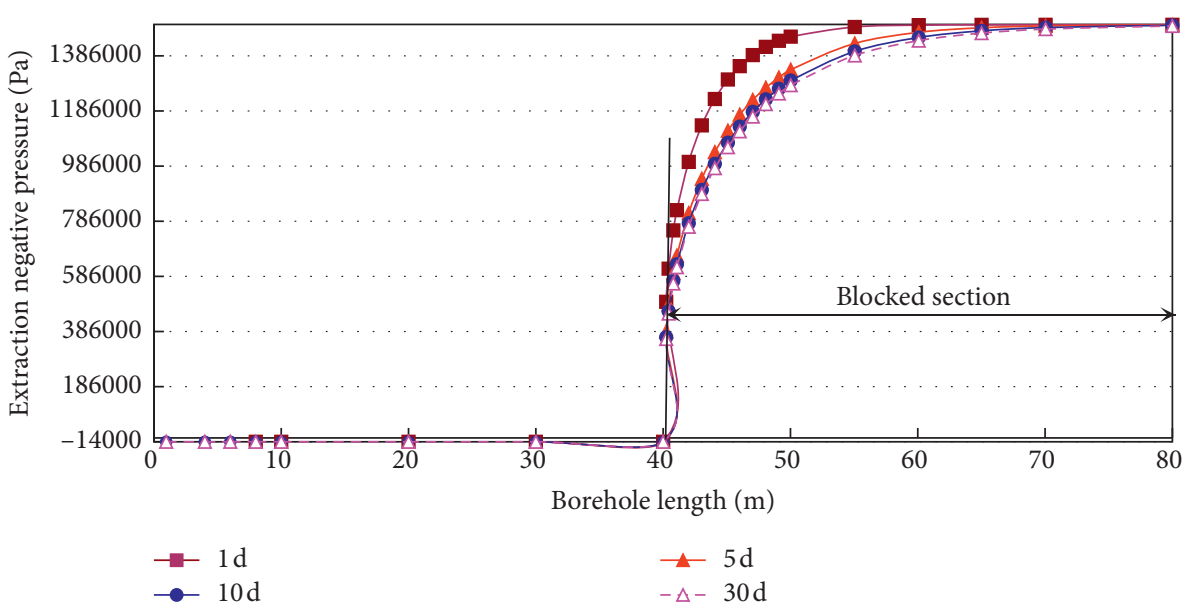

Figure 10: The gas extraction pressure distribution of plug hole.

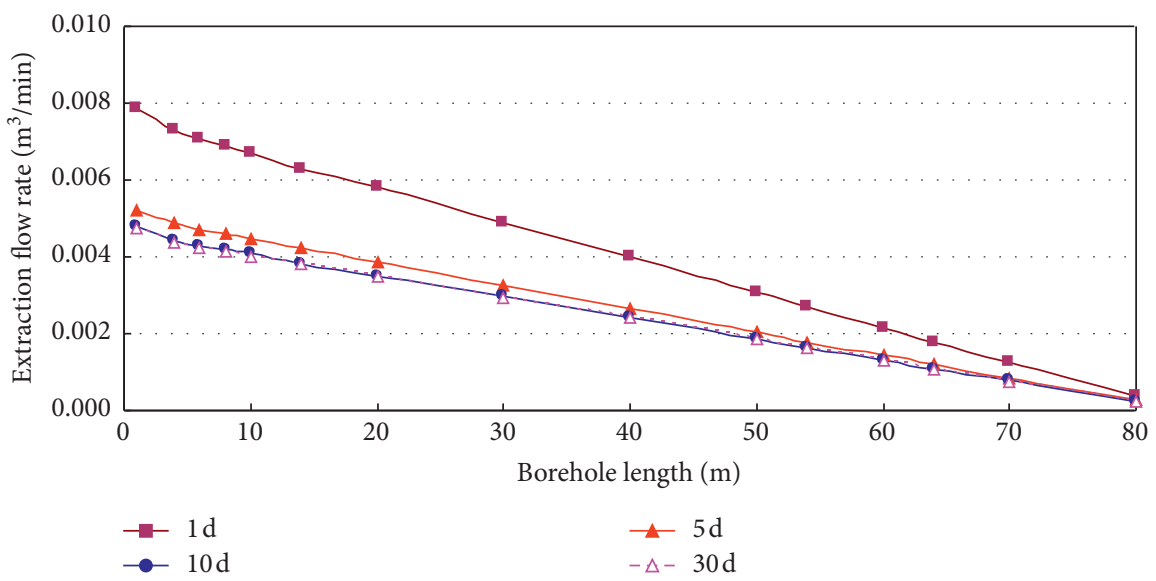

FIgURE 11: The drainage flow distribution of complete hole along the borehole length.

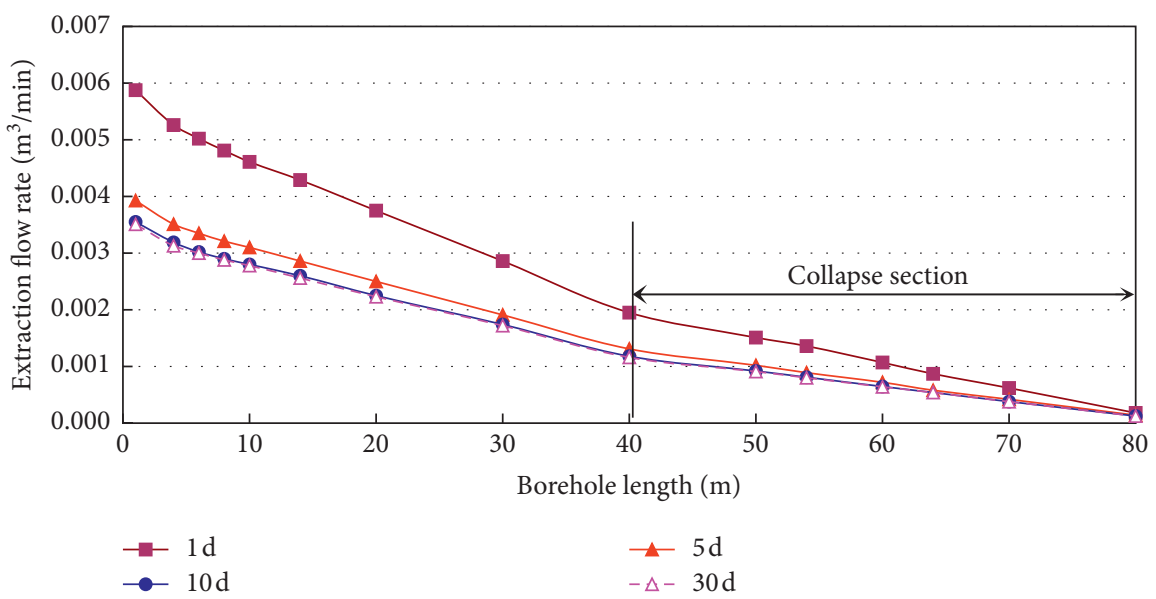

Figure 12: The drainage flow distribution of collapsed hole along the borehole length.

complete segment and remains negative, while the drainage pressure of the plug segment becomes positive, and that closer to the borehole bottom is closer to the original gas pressure.
4.3.3. Effect of Deformation Instability of Gas Drainage Borehole on Gas Drainage Effect. When there is no borehole deformation (i.e., complete hole), collapsed hole, or plug 


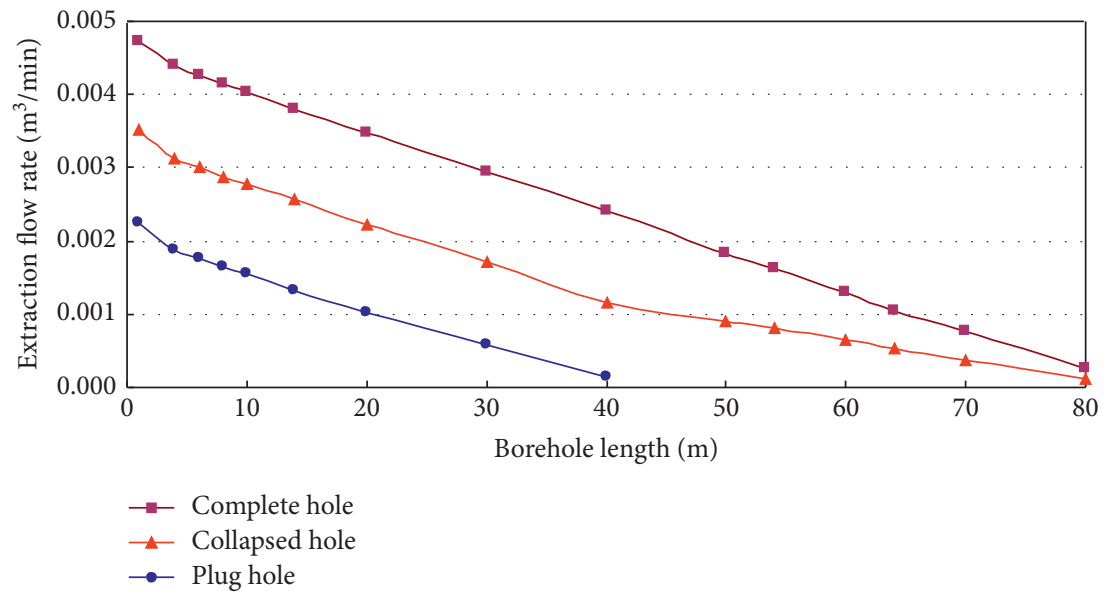

FIgURE 13: The drainage flow distribution of borehole along the borehole length for 30 days after extraction.

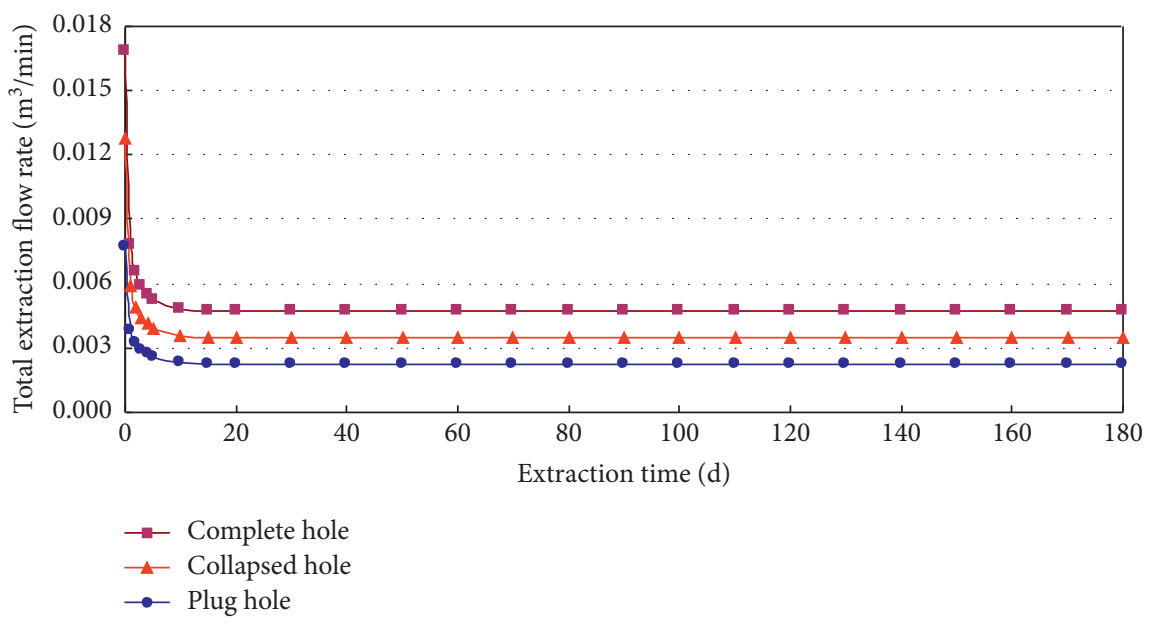

Figure 14: The total flow change of complete hole, collapsed hole, and plug hole.

hole, the drainage flow distribution of the borehole is shown in Figures 11 and 12 for different drainage time.

It can be seen from Figure 11 that the borehole drainage flow is roughly in linear distribution along the hole length. The drainage flow is smaller if the borehole is farther from the aperture. The borehole drainage flow decreases with the increasing drainage time but stabilizes finally.

It can be seen from Figure 12 that drainage flow decreases with the extension of drainage time and then stabilizes in case of borehole collapse. The drainage flow still decreases as the distance from the aperture increases, but the drainage flow is no longer in linear distribution along the hole length but with slight turning point at the junction between the collapse segment and the normal segment. Compared with the decreasing extent of complete segment drainage flow along the hole length, that of collapse segment is slower. However, compared with the complete hole, the latter has decreased total drainage flow, which means that gas drainage effect will be worse in case of hole collapse.

When there is no borehole deformation (i.e., complete hole), collapsed hole, or plug hole, the borehole drainage flow distribution along the hole length and its total flow change after one month of drainage are shown in Figures 13 and 14 .

It can be easily seen from Figures 13 and 14 that the drainage effect is ideal for complete hole but worse for borehole collapse, which renders borehole aperture smaller. In case of borehole plug, the drainage effect is poorer, owing to the reduced effective drainage length.

\subsection{Suction Pressure Distribution of the Drainage System in the} Field Test. The bunch of pipes method can be used to test the negative pressure at different depth in the borehole in the field. As shown in Figure 15, we put a group of copper tubes of different length into the borehole, record the position of each copper tube, and measure negative pressure at different depth of hole with U-type mercury column meter.

The gas extraction negative pressure distribution of bedding borehole for 1 day after extraction was measured by bunch of pipes method in the $\mathrm{JI}_{15}-21030$ working face. The test results are shown in Figure 16.

As can be known from Figure 16, the suction pressure loss is small within $40 \mathrm{~m}$ from the borehole, it suddenly 


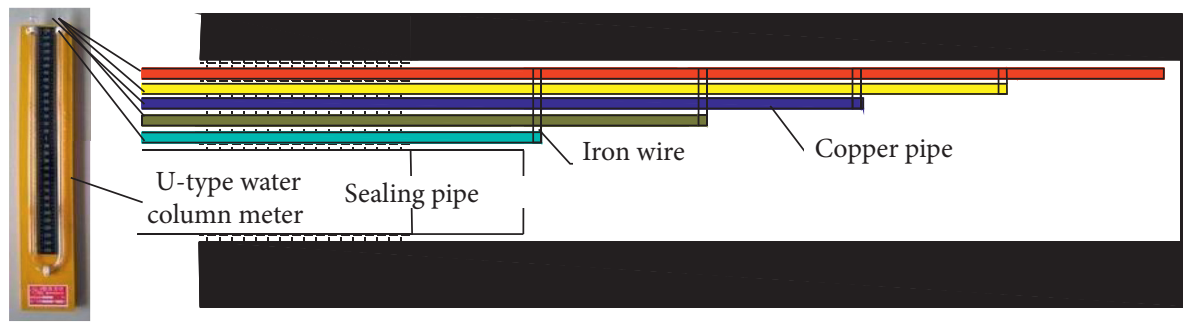

FIGURE 15: Schematic diagram about using bunch of pipes method to test negative pressure distribution.

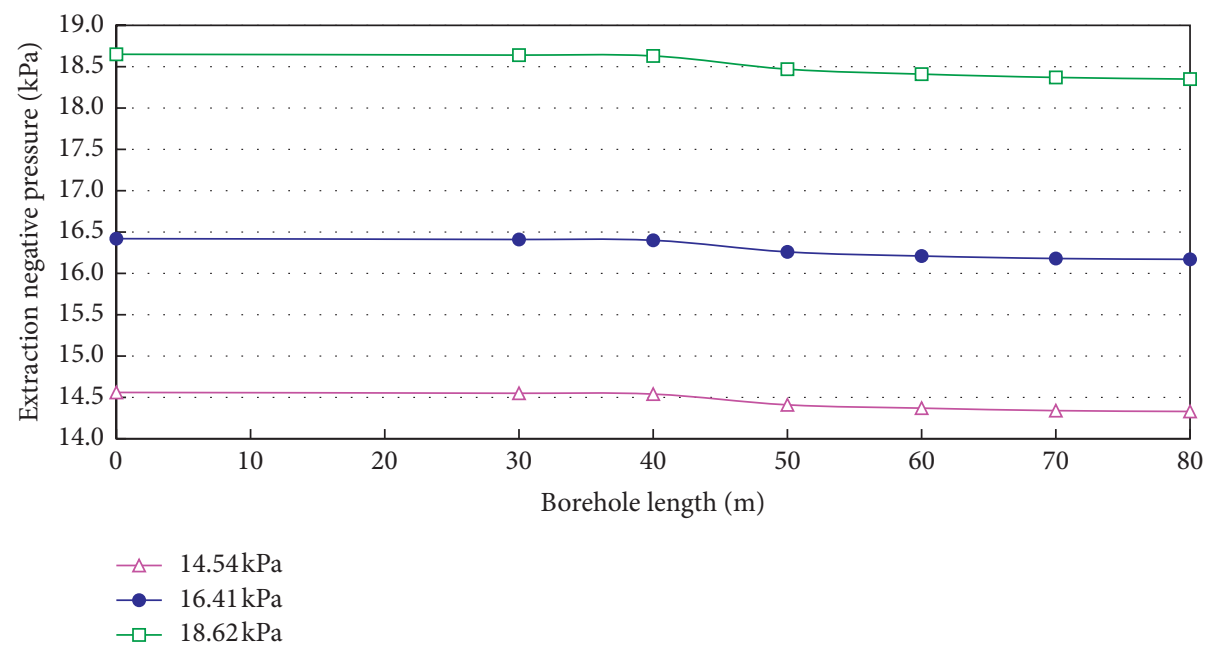

Figure 16: The gas extraction negative pressure distribution of borehole along the borehole length for 1 day after extraction.

increases $40 \mathrm{~m}$ away from the hole, and it is even bigger within $40 \mathrm{~m}$ from the bottom, which is consistent with the suction pressure distribution law in case of collapse at the bottom. It can be inferred from the magnitude of suction pressure loss that great collapse occurs in the rear $40 \mathrm{~m}$ of the borehole, i.e., a serious hole collapse. In this case, the smaller effective gas circulation area in the borehole leads to greater suction pressure loss.

\section{Conclusion}

(1) The deformation instability mechanism of soft coal seams is analyzed, and three deformation instability modes are proposed for soft coal seams, namely, complete holes, collapse holes, and plug holes. A solid-fluid coupling model incorporating dynamic change of borehole suction pressure is established. The effects of the three deformation instability modes of gas drainage borehole on gas drainage are analyzed.

(2) Collapsed hole at the hole bottom exerts little effect on coal-bed gas drainage. In case of borehole collapse, the suction pressure loss is big at the collapse segment, and the total suction pressure loss of the drainage system in the borehole is bigger than that in the complete hole. However, it is smaller than the suction pressure of the drainage system and exerts limited effect on gas drainage. As the borehole collapse deteriorates, the effective drainage section of the borehole becomes smaller, while the suction pressure loss in the borehole increases continuously; thus, the gas drainage effect continuously worsens. Compared with coal-bed gas pressure distribution of complete hole, gas pressure distribution in case of collapsed hole differs only at the collapsed hole segment.

(3) Borehole plugging at the hole bottom exerts big effect on coal-bed gas drainage. In case of plug hole, a continuous medium forms between the plug segment coal body and the surrounding coal seam, the plug segment drainage pressure turns into coal-bed gas pressure, and effective drainage length of the borehole shortens, seriously affecting the gas drainage effect. Borehole plugging has a great influence on gas pressure distribution in coal seam, and it cannot play the role of drainage and pressure relief in the section of borehole plugging. The research results can be used to monitor the instability region and the degree of borehole instability.

\section{Data Availability}

The data used to support the findings of this study are available from the corresponding author upon request.

\section{Conflicts of Interest}

The authors declare that they have no conflicts of interest. 


\section{Acknowledgments}

This study was supported by the National Key Research and Development Program of China (2018YFC0808103), the National Natural Science Foundation of China (grants nos. 51734007, 51704099, and 52074106), the Program for Innovative Research Team in University of Ministry of Education of China (grant no. IRT_16R22), the Key R\&D and Promotion Projects in Henan Province (grant no. 212102310105), and the Doctoral Fund of Henan Polytechnic University (grant no. B2019-56).

\section{References}

[1] Y. Sun, Y. L. Wang, X. S. Di, and X. F. Wang, "Analysis on reasons of drilling difficulty in soft and outburst coal seam," Journal of China Coal Society, vol. 37, no. 1, pp. 117-121, 2012.

[2] L. Chun, Study on Mechanism and Controlling of Borehole Collapse in Soft Coal Seam, China University of Mining and Technology, Xuzhou, China, 2014.

[3] L. Yuan, "Strategic thinking of simultaneous exploitation of coal and gas in deep mining," Journal of China Coal Society, vol. 41, no. 1, pp. 1-6, 2016.

[4] H. Zhao, M. Chen, Y. Li, and W. Zhang, "Discrete element model for coal wellbore stability," International Journal of Rock Mechanics and Mining Sciences, vol. 54, pp. 43-46, 2012.

[5] T. Zhang, Study on Nonlinear Mechanical Mechanism of Mining Instability of Gas Rich Coal and Rock Mass, Xi'an University of Science and Technology, Xi'an, China, 2009.

[6] K. Tezuka and H. Niitsuma, "Stress estimated using micro seismic clusters and its relationship to the fracture system of the Hijiori hot dry rock reservoir," Engineering Geology, vol. 56, no. 1-2, pp. 47-62, 2000.

[7] Z. Wang, Y. Liang, and H. Jin, "Analysis of mechanics conditions for instability of outburst-preventing borehole," Journal of Mining \& Safety Engineering, vol. 25, no. 4, pp. 444-448, 2008.

[8] Y. Shengqi, J. Hongwen, and X. Tao, "Mechanical behavior and failure analysis of brittle sandstone specimens containing combined flaws under uniaxial compression," Journal of Central South University, vol. 21, no. 5, pp. 2059-2073, 2014.

[9] S. Yang, X. Liu, and Y. Li, "Experimental analysis of mechanical behavior of sandstone containing hole and fissure under uniaxial compression," Chinese Journal of Rock Mechanics and Engineering, vol. 31, no. 2, pp. 3539-3546, 2012.

[10] Z. Cheng, Q. Li, S. Chen, G. H. Ni, and W. Yang, "Analysis on borehole instability and control method of pore forming of hydraulic fracturing in soft coal seam," Journal of China Coal Society, vol. 39, no. 9, pp. 1431-1436, 2012.

[11] X. Yao, G. Cheng, and B. Shi, "Analysis on gas extraction drilling instability and control method of pore forming in deep surrounding rock with weak structure," Journal of China Coal Society, vol. 35, no. 12, pp. 2073-2081, 2010.

[12] F. C. Hao, G.-H. Zhi, and L.-J. Sun, "Stress distribution and movement law around drainage borehole when considering rheological property," Journal of Mining \& Safety Engineering, vol. 30, no. 3, pp. 449-455, 2013.

[13] S. Wang, D. Mao, and Y. Ren, "Parameter optimization of drilling holes for pressure relief," Coal Mining Technology, vol. 15, no. 5, pp. 14-17, 2010.

[14] X. Feng and Q. Zhang, "The effect of backfilling materials on the deformation of coal and rock strata containing multiple goaf: a numerical study," Minerals, vol. 8, no. 6, p. 224, 2018.
[15] X. Feng, Q. Zhang, E. Wang, M. Ali, Z. Dong, and G. Zhang, "3D modeling of the influence of a splay fault on controlling the propagation of nonlinear stress waves induced by blast loading," Soil Dynamics and Earthquake Engineering, vol. 138, Article ID 106335.

[16] W. Zhao, K. Wang, R. Zhang, H. Dong, Z. Lou, and F. An, "Influence of combination forms of intact sub-layer and tectonically deformed sub-layer of coal on the gas drainage performance of boreholes: a numerical study," International Journal of Coal Science \& Technology, vol. 7, no. 4, pp. 1-10, 2020.

[17] X.-B. Zhang, W.-Y. Wang, and M. Yang, "Study on deformation and destabilization characteristics and modes of drainage borehole," Energy Sources, Part A: Recovery, Utilization, and Environmental Effects, vol. 42, no. 19, pp. 24482459, 2019.

[18] X. Zhang, W. Wang, M. Yang, H.-H. Cai, J. Liu, and S. Shen, "Study on mechanical failure and permeability characteristics of porous gas-bearing coal under triaxial stress," Shock and Vibration, vol. 2020, Article ID 8838966, 10 pages, 2020.

[19] X. Wu, Y. Peng, J. Xu, Q. Yan, W. Nie, and T. Zhang, "Experimental study on evolution law for particle breakage during coal and gas outburst," International Journal of Coal Science \& Technology, vol. 7, no. 1, pp. 97-106, 2020.

[20] C. Wu, C. Yuan, G. Wen, L. Han, and H. Liu, "A dynamic evaluation technique for assessing gas output from coal seams during commingling production within a coal bed methane well: a case study from the Qinshui Basin," International Journal of Coal Science \& Technology, vol. 7, no. 1, pp. 122132, 2020. 